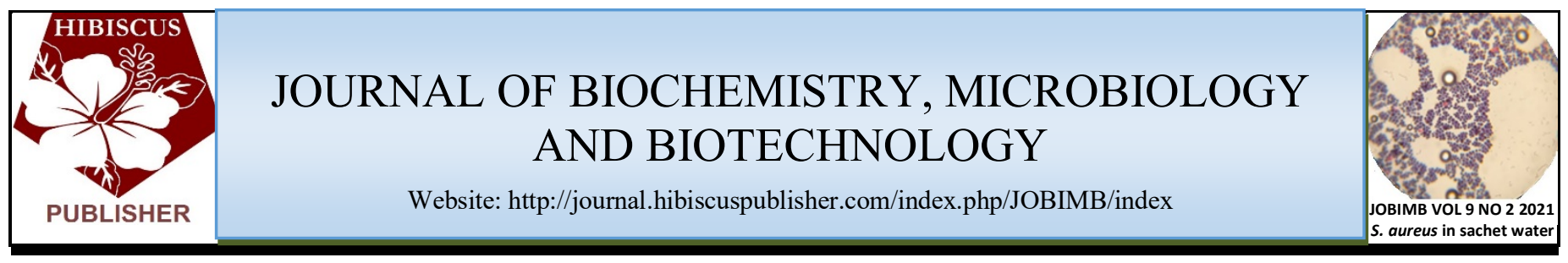

\title{
The Use of Plants, Nanotechnology and Surfactants in Lindane Remediation: A Mini Review
}

\author{
Garba $\mathrm{Uba}^{1 *}$ and Abdussamad M. Baba ${ }^{2}$ \\ ${ }^{1}$ Department of Science Laboratory Technology, College of Science and Technology, Jigawa State Polytechnic, \\ Dutse, PMB 7040, Nigeria. \\ ${ }^{2}$ Department of Biology, Aminu Kano College of Islamic Legal Studies, Kano, Nigeria. \\ *Corresponding author: \\ Garba Uba \\ Department of Science Laboratory Technology, \\ College of Science and Technology, \\ Jigawa State Polytechnic, Dutse, \\ PMB 7040 \\ Email: garbauba@jiigpoly.edu.ng
}

\begin{tabular}{l}
\hline HISTORY \\
Received: $14^{\text {th }}$ Oct 2021 \\
Received in revised form: $2^{\text {nd }}$ Dec 2021 \\
Accepted: $20^{\text {th }}$ Dec 202 \\
\hline KEYWORDS \\
Plants \\
Phytoremediation \\
Nanotechnology \\
Surfactants \\
Lindane Remediation
\end{tabular}

\begin{abstract}
Lindane is an organochlorine chemical and an isomer of hexachlorocyclohexane that has been used both as an agricultural insecticide and as a pharmaceutical treatment for lice and scabies. Lindane accumulates in the agricultural soil and plants thereby causing environmental and health deteriorative effects. A lot of soil remediation methods used are highly expensive and require a lot of expertise. Phytoremediation (rhizofiltration, phytostabilization), which involve the use of the plant to stabilize or remove environmental toxicants is presently much in use because of its cost-effectiveness and ecological friendliness. Adsorption has emerged as the most efficient, easy, and promising nanotechnology method of wastewater treatment out of the several approaches now employed. Recently, biosurfactants are used for the production of nanoparticles which will be further applied in the area of pesticide remediation. The use of phytoremediation is the most important fully green approach as no new chemicals are added to the polluted soil. Other emerging technologies where phytoremediation might not be applicable especially groundwater has begun to evaluate the use of green nanobiotechnology.
\end{abstract}

\section{INTRODUCTION}

This hazard to human and environmental health has grown significantly during the past few decades. Because to contamination in the soil, billions of acres of otherwise productive land remain uncultivated. It is, however, costly and disruptive to the soil to use standard remediation methods to clean up polluted property [1]. Natural and cost-effective treatment of polluted soil using phytoremediation is an intriguing option. Using green plants to remove organic contaminants, harmful heavy metals, or excess minerals from polluted soil or water is a new developing technique [2].

A lot of the current soil-cleansing methods in use today are highly expensive. Soil cleaning costs around $\$ 250$ per cubic yard, whereas incineration to remove explosives costs around $\$ 1,020$ per cubic yard [3]. Since phytoremediation is estimated to cost $\$ 80$ per cubic yard, it is clear why this approach has received so much attention. In many cases, traditional remediation methods have proved impracticable or prohibitively expensive, making phytoremediation a more viable option for hazardous waste removal [4]. There are several toxins that may be remedied by phytoremediation, including various metals and organic pollutants. Unlike typical soil remediation methods, phytoremediation requires no particular training or equipment allowing it to be employed on nearly any contaminated site [5].

An additional benefit of phytoremediation is its ability to decrease the volume of waste that must be removed[6]. Removing the soil up to a certain depth and putting it in a hazardous landfill is a standard treatment for areas polluted with heavy metals [7]. The environment is severely impacted by this procedure. Harvesting and burning plants that absorb heavy metals results in just a tiny percentage of the soil mass or volume that would have been eliminated, while creating a minimum environmental disturbance. Consequently [3]. It is less harmful to the ecosystem to employ plants to clean the soil rather than chemicals, as the topsoil is still productive. By establishing ground cover on polluted locations, this approach reduces the danger of exposure to potentially harmful substances by wind and water erosion [8].

Although phytoremediation has significant benefits over traditional soil remediation procedures, there are certain limits to consider when comparing them to conventional soil remediation methods. When a substantial amount of pollution is present in the soil, it may be necessary to grow a large number of crops in order to completely eliminate it [9]. This might take several years to 
complete because it is time-consuming and perhaps longer. The use of phytoremediation is not an option when the land is required for real estate development that cannot be postponed for a period of time of more than a few years. As a result, plants that absorb heavy metals may harm animals, causing them to die. If the metals make their way into the food chain, they might endanger human health [3].

\section{Biological processes are employed in the process of phytoremediation}

Rhizofiltration, phytostabilization, phytodegradation, and phytoextraction are all methods of phytoremediation that can be used in conjunction with one another. Plant roots are used in the process of absorbing or adsorbing contaminants from water and aqueous waste streams. Rhizofiltration is a technology used to accomplish this goal[10]. When plant roots absorb and store soil contaminants, they help to prevent environmental pollution such as heavy metal leaching into groundwater and the spread of polluted dust due to wind erosion, both of which are harmful to the environment. Phytostabilization is a term used to describe the process of plants becoming more stable [11]. Both of these processes are efficient in some instances, but neither of them is capable of removing a significant amount of contaminant from the soil at one time [12]). The majority of the time, phytodegradation or phytoextraction are employed in the cleanup of contaminated environments.

The phytodegradation of pesticides, explosives, and organic solvents is a process in which plants' metabolic activities break down chemicals. Contaminants that have been degraded by the environment are released into the atmosphere through transpiration [13]. The distinct enzymes produced by different plant species are responsible for determining how rapidly organic molecules may be degraded or broken down. Poplar trees contain enzymes that are capable of degrading pesticides such as atrazine, a regularly used herbicide that poses a significant environmental threat. According to research conducted by the University of Iowa, poplar trees may remove up to 20 per cent of atrazine from the soil by absorbing and metabolising the pesticide through the roots of the trees. Additional to this, poplar trees emit sugars and other organic compounds such as alcohols and volatile acids that stimulate bacteria to degrade atrazine near their roots, a process known as Rhizodegradation [14].

It is primarily focused on densely rooted, fast-expanding grasses and plants with fine root systems, such as Brassica sp. Morus alba L. and Populus deltoides trees have been effectively exploited in the synthesis of chlorophenols and chlorinated solvents, as well as phenols [15] Carbon is responsible for xenobiotic metabolism in these species through reductive dehalogenation. Plants and microorganisms work together to break down, detoxify, and ultimately remove environmental pollutants. According to the EPA, in addition to abiotic elements (temperature, soil moisture, $\mathrm{pH}$, and so on), the microbial/plant community and pesticide characteristics all influence pesticide metabolism. Abiotic degradation happens as a result of various chemical and physical alterations caused by processes such as hydrolysis, photolysis, oxidation, reduction, and rearrangements, among others. Enzymatic transformation, which happens predominantly through the pathways of phytoremediation and microbial detoxification, is a fundamental component of pesticide biotic breakdown [16]. Plants can break down pesticides in a variety of ways, including pesticide metabolism in the rhizosphere, which has been demonstrated. In the case of $P$. chrysosporium, a ligninolytic fungus, a putative cytochrome P450 enzyme is responsible for oxidising the insecticide lindane, for example[17]. The term "oxidative transformation" refers to a process in which, for example, the fungicide feripromorph's metabolism can be carried out by the oxidative enzymes found in cytochrome P450. Among the other methods are the hydrolytic transformation reaction [18], ester hydrolysis of thifensulfuronmethyl using plant estrases with the GlyXSerGly motif [19], and aromatic nitroreductive metabolism of pentachloronitrobenzene in peanut (Arachis hypogaea) [20]. The glutathione conjugation process, which occurs in the presence of plants, can also aid in their recovery. Increasing the quantity of glutathione, also known as GSH (L-glutamyl L-cysteinyl Glycine), in wheat was discovered to protect it from phenoxaprop, a pesticide [21].

Plants may improve the cometabolism of agricultural pollutants in the rhizosphere by one of the following mechanisms: I it may allow selective enrichment of low-density degrader organisms to significantly degrade xenobiotics in root free soil [22], (ii) it may enhance growth-linked metabolism or stimulate microbial growth by providing a natural substrate when the concentration of xenobiotics is low or unavailable [23]. [24] used the genome sequences of nine Sphingobium strains collected from HCH dumpsites (LL03, DS20, IP26, HDIPO4, $\mathrm{P} 25$, and RL3) as well as the genome sequences of three existing strains in their analysis (S. indicum B90A, S. japonicum UT26S, and Sphingobium sp. SYK6). It was revealed that the spinach plant may be utilised to phytoextract lindane [25]. Their findings demonstrated a statistically significant difference in lindane dissipation between vegetated and unvegetated soils. Aresta et al. determined the lindane bioremediation ability of the demosponge Hymeniacidon perlevis to bioremediate lindane-polluted sea water and degradation analysed by solid phase microextraction (SPME) and gas chromatography-mass spectrometry (GC-MS) of lindane-polluted sea water and degradation collected and analysed by solid phase microextraction (SPME) and gas chromatography-mass [25] .

\section{Plant-microbe interactions}

Plants, like microbes, have been found to have an extraordinary ability to remove or immobilise different isomers of $\mathrm{HCH}$ from the environment. Plant-based bioremediation systems, which are based on interactions between plants and their associated bacteria, have been described as both cost-effective and environmentally acceptable methods of cleaning up polluted areas in recent years [27].

Organic pollutants such as $\mathrm{HCH}$ have been removed from the environment utilising microbe-assisted phytoremediation, which has proven to be a highly successful technology. [28] studied the removal of $\mathrm{HCH}$ from a resistant leguminous shrub (Cytisus striatus) in conjunction with numerous microbial inoculant treatments and discovered that $\mathrm{HCH}$ dissipation was improved in potted plants. After seeding the substrates with Cytisus striatus, they injected them with Rhodococcus erythropolis ET54b and Sphingomonas sp. D4. According to the authors' article, the substrates was planted with $C$. striatus which displayed better detoxification of $\mathrm{HCH}$ isomers and that both microorganisms protected the plants against the damaging effects of the pollutant. It was also stated that if done appropriately, inoculating $C$. striatus with this combination of bacterial strains could be a promising strategy for cleaning up $\mathrm{HCH}$-contaminated sites [29]. [30] discovered unique dechlorinase activity in Zea mays root exudates, which when combined with Streptomyces strains resulted in improved lindane removal from the liquid medium. They investigated the effect of maize REs on the growth of Streptomyces spp. A5 and M7, as well as the removal of hydroxychlorohydrin $(\mathrm{HCH})$. It has been proposed that these 
microorganisms are competitive at the rhizosphere level based on their ability to grow on minimal media supplemented with maize REs as the sole carbon source. Fungi, which grow in a symbiotic relationship with plants, have created unique enzyme pathways that aid in the breakdown of pesticides that bacteria alone cannot convert [31]. Mycorrhizal fungi, which create symbiotic relationships with a wide variety of plant species, can help plants grow and survive by reducing stress caused by a variety of toxins in the environment. The consequences of lindane contamination on flora and the arbuscular mycorrhizae that are associated with it, according to [32]. According to these findings, preinoculation of four plant species with Glomus deserticola, an isolate of which was isolated from $\mathrm{HCH}$-contaminated soil, resulted in increased root development and fungal colonisation. The fungus, according to the study's findings, increases the plant's tolerance to the hazardous effects of the soil environment.

A study used comparative genomics to define the Hexachlorocyclohexane catabolic pathway in eleven Sphingomonadaceae strains [33]. In this study, a horizontal transfer of genes mediated by the insertion sequence IS6100 and acquired in the pathway was demonstrated. IS6100 has been linked to lin genes in new strains from the Czech Republic, according to this study. [34] discovered that when three plant growth regulators, indolebutyric acid (IBA), thidiazuron (TDZ), and gibberellic acid (GA3), were added individually or in pairwise combinations, lindane degradation was greatly enhanced. According to their findings, $\mathrm{HCH}$ concentrations in bulk soil planted with corn seeds pretreatment with GA3 or TDZ + GA3 were decreased by up to 97.4 per cent and 98.4 per cent, respectively, whereas $\mathrm{HCH}$ removal in soil planted with non pretreated control waxy corn seeds was only 35.7 percent. According to the findings of this investigation, LinA appears to be engaged in phytoremediation and hydroxychlorohydrin degradation in the environment. The linA gene was cloned in a hairy root culture of the plant Cucurbita moschata, as demonstrated in this work [35]. [36] genetically engineered the Pseudomonas putida strain KT2440 to achieve full mineralization of the chemicals methyl parathion (MP) and hexachlorocyclohexane $(\mathrm{HCH})$. The mineralization paths were built in this study using the functional assembly of the MP and $\mathrm{HCH}$. [37] studied the synergistic rhizosphere degradation of hexachlorocyclohexane using a plant-fungal interaction model. In addition to Aspergillus niger (KY693970), other strains included Talaromyces purpurogenus (KY488468), Yarrowia lipolytica (KY488469), Talaromyces atroroseus (KY488464), and Aspergillis flavus (KY488464) (KY693973). In several combinational investigations, it was revealed that the combined rhizospheric action of $M$. maximus and the fungi increased the rate of lindane breakdown by up to $79.76,85.93$, and 88.67 percent, respectively.

\section{Nanobiotechnology}

Pesticide leaching and persistence is the main source of organic pollution in the environment. As a result of their toxicity, industrial wastewaters are also significant sources of pesticide pollution in aquatic systems, which poses a considerable threat to the general public's health [38]. It has been established that there are several strategies to remove pesticides from the aquatic environment, such as ozonation, membrane separation and the use of oxidation [39]. Pesticides must be converted into innocuous substances like $\mathrm{CO}_{2}$ and $\mathrm{H}_{2} \mathrm{O}$ since these procedures do not eliminate pesticides completely. To attain high clearance rates, cost-effective and ecologically friendly methods must be designed and implemented. Adsorption has emerged as the most efficient, easy, and promising method of wastewater treatment out of the several approaches now employed. Intended for organic contamination removal, it is easy to execute [40].

It has recently emerged as a potential new technology for the degradation of organic pollutants through the use of semiconductors and photon energy, heterogeneous photocatalysis. By this hypothesis, electrons in the valence band are promoted to conduction band when a semiconductor is illuminated with a light source of a certain wavelength is exposed. They move to the semiconductor's surface, where they break down organic impurities, resulting in harmless chemical production [41].

Nanotechnology has a wide range of applications, including environmental studies and medical treatments. In spite of their tiny size, nanoparticles demonstrate a wide range of complex features, such as their size, shape and other size-dependent properties [42]. In the last several years, nanoparticles have been employed to improve water treatment systems. The link between material quality and filler size has climbed to the top of the list of research goals due to recent advances in nanotechnology. This is only one of the examples where nanotechnology can be used in toxic remediation including pesticides.

Integrated nanobiotechnological methods for pesticide treatment are becoming increasingly popular as an innovative and successful technology because microbial cultures have the capacity to break down $\mathrm{HCH}$. It is proposed that zerovalent granular iron or iron nanoparticles be used in conjunction with organochlorine pesticides for catalytic reductive dehalogenation of a variety of organochlorine insecticides $[5,43]$. An integrated nanobiotechnological strategy for drinking water treatment was developed in one study, using FeS nanoparticles produced by a wet chemical technique and stabilised by a fungal polymer. The goal was to eradicate pesticide residues by using an integrated nanobiotechnological strategy. They dechlorinated lindane, which was then mineralized by a bacterial culture, which also degraded the fungal polymer as a result of the action of the FeS nanoparticles. Groundwater treatment using lindane dechlorination in a multiphase catalytic reduction system with palladium-platinum-nickel nanocatalyst has been claimed to be a successful approach for removing pesticide residues from groundwater [44].

A study used an integrated nanobiotechnology approach to degrade lindane from polluted soil in India, and the results were promising [45]. As part of a partnership with Sphingomonas sp. strain NM05, we were able to successfully break down lindane using stabilised $\mathrm{Pd} / \mathrm{Fe}(0)$ bimetallic nanoparticles $(\mathrm{CMCPd} / \mathrm{Fe}(0))$. It appears that the integrated technique has the potential to be a viable alternative treatment tool for lindanecontaminated soil, based on their findings so far. According to [46], a new bionano system based on nanoscale zinc oxide was used to detect lindane breakdown (nZnO). Ferrate, another nanotechnological discovery, has been utilised as a chemical reagent for the treatment of lindane-contaminated water, and it has been shown to be effective. This is due to the fact that they have a high oxidation potential and produce no hazardous byproducts. It has been reported that the degradation of lindane in the presence of ferrate was investigated and that the synthesis of lindane metabolites such as trichlorobenzenes and pentachloro-cyclohexenes was observed [47]. A method developed by [48] for the degradation of lindane and hexachlorobenzene was based on palladium nanoparticles stabilised in microcellular high-density polyethylene (HCB). The nonreductive dechlorination of lindane by nitrogen-containing multiwall carbon nanotubes (NMWCNTs) (CNTN1 and CNTN2) in the $\mathrm{pH}$ range of 7.0 to 9.0 was explored in another 
research, and the responsible nitrogen species for lindane dehydrochlorination under environmental factors were observed as amine and pyridinic nitrogen species. The accelerated degradation was due to the presence of amine and pyridinic nitrogen species in the environment. This might target the hydrogen atom that is related to the -carbon, and lindane dehydrochlorination could be accomplished through an elimination process [49]. However, despite the fact that the biotechnological technology used for organochlorine pesticide biodegradation is a promising and successful technique, it has a number of important disadvantages. The precipitation of metal hydroxides on iron, for instance, diminishes the reactivity of the metal while increasing the toxicity of the released chemicals [50].

\section{Degradation by biosurfactants}

Biosurfactants are extracellular or membrane-bound surfaceactive compounds that are mainly produced by bacteria yeast and fungi. These are amphiphilic in nature and possess a variety of chemical structures based on their physicochemical properties such as fatty acids, neutral lipids, phospholipid, glycolipids, lipopeptides and other polymeric molecules [51]. Microbialbased remediation techniques for lindane-contaminated environments prove to be cost-effective and environment friendly approach where the microorganisms or their products like enzymes lead to chemical changes in these molecules. These amphiphilic biomolecules reduce the surface tension in the air/water interfaces and reduce the interfacial tension in oil/water interfaces [52].

Recently, biosurfactant (Glycolipids, Rhamnolipids, Glucose lipids, Trehalolipids, Sophorolipids, Mannosylerythritol lipids, polyol lipids, Diglycosyldiglycerides, Flavolipids) and biosurfactant producing microbes (Pseudomonas aeruginosa, Rhodococcus erythropolis, $R$. ruber, $R$. wratislaviensis, Corynebacterium sp., Mycobacterium sp., Arthrobactor sp., Candida lipolytica, Flavobacteirum sp.) are used for production of nanoparticles which will be further applicable in the area of pesticide degradation [53]. The area of the biosurfactantmediated process of nanoparticle synthesis is emerging as part of remediation biotechnology [54]. Biosurfactants can replace the harsh surfactant presently used in pesticide industries as these natural surfactants are found to be utilized as carbon source by soil inhabiting microbes [55].

Pesticide biodegradation is supported by the addition of surfactant induces the degradation of chlorinated hydrocarbon supported by glycolipids. Biosurfactant from Lactobacillus pentosus has demonstrated reduction by $59-63 \%$ of octane hydrocarbon from soil, thus exhibiting the biodegradation accelerator property of biosurfactant[56]. It has been observed that a biosurfactant producing species of Burkholderia isolated from oil contaminated soil may be a potential candidate for bioremediation of a variety of pesticide contamination including lindane [55]. Many researchers have observed that the efficiency of biosurfactants in the removal of organic insoluble pollutants from soil is more as compared to synthetic surfactants. Despite the broad applications of chemical surfactants, they are environmentally hazardous and lead to ecological imbalance when accumulated above a limited concentration. In such conditions, the performance of biosurfactants is most promising and eco-friendly and hence they can act as an effective alternative to chemical surfactants [57].

Microemulsion is one form of surfactant and in one study, it has been shown to be useful in the removal of high quantities of lindane from both soil and water systems. With Tween 80, 1pentanol, and three vegetable oils, three stable microemulsions were effectively created. Lindane's solubilization was promoted by increasing the cosurfactant/surfactant ratio in microemulsions while increasing the oil/surfactant ratio was detrimental. As much as 4.5 times more lindane was soluble in the soybean oilbased microemulsion than it was in the surfactant-based solution at the same concentration [58]. With this microemulsion, the bioavailability of lindane in water was increased almost two-fold, allowing Streptomyces sp M7 to remove it from the water more effectively. Although the inclusion of the microemulsion resulted in an $87 \%$ reduction in the concentration of Streptomyces sp. M7 lindane, it did not have a significant effect on the removal of lindane from the soil without the addition of surfactant agents [49,59].

\section{CONCLUSION}

Lindane is a toxic pesticide that has been phased out in many countries. Despite this, its usage is still reported in underdeveloped countries. This warrants the finding of green technologies to remediate lindane. The use of phytoremediation is an important fully green approach as no new chemicals are added to the polluted soil. Other emerging technologies where phytoremediation might not be applicable especially groundwater has begun to evaluate the use of green nanobiotechnology. Aside from phytoremediation, the use of microorganisms either alone or in conjunction with plants and nanobiotechnology is extensively being explored.

\section{REFERENCES}

1. Wan $X$, Lei $M$, Chen $T$. Cost-benefit calculation of phytoremediation technology for heavy-metal-contaminated soil. Sci The Total Environ . 2016;563-564:796-802.

2. Nweke OC, Sanders III WH. Modern Environal Health Hazards: A Public Health Issue of Increasing Significance in Africa. Environal Health Perspectives . 2009;117(6):863-70.

3. Pirzadah TB, Malik B, Tahir I, Kumar M, Varma A, Rehman RU. Phytoremediation. In: Soil Remediation and Plants .; 2015. p. $107-$ 29.

4. Surriya O, Sarah Saleem S, Waqar K, Gul Kazi A. Phytoremediation of Soils. In: Soil Remediation and Plants .; 2015 p. 1-36.

5. Zhang W-X. Nanoscale iron particles for Environal remediation: An overview. J Nanoparticle Res. 2003;5(3-4):323-32.

6. Clemens S, Palmgren MG, Krämer U. A long way ahead: understanding and Eng plant metal accumulation. Trends in Plant Sci . 2002;7(7):309-15.

7. Wu JT, Leung K, Leung GM. Nowcasting and forecasting the potential domestic and Intl spread of the 2019-nCoV outbreak originating in Wuhan, China: a modelling study. The Lancet . 2020 Feb;395(10225):689-97.

8. Assunção AGL, Martins PDC, De Folter S, Vooijs R, Schat H, Aarts MGM. Elevated expression of metal transporter genes in three accessions of the metal hyperaccumulator Thlaspi caerulescens: Zinc transporters of Thlaspi caerulescens. Plant, Cell \& Environ . $2001 \mathrm{Feb}$;24(2):217-26.

9. Pandey SN. Accumulation of heavy metals $(\mathrm{Cd}, \mathrm{Cr}, \mathrm{Cu}, \mathrm{Ni}$ and $\mathrm{Zn})$ in Raphanus sativus L. and Spinacia oleracea L. plants irrigated with industrial effluent. J Environ Biol. 2006 May;27(2 Suppl):381-4.

10. Srivastava S, Anand V, Singh P, Roy A, Pallavi S, Bist V, et al Microbial systems as a source of novel genes for enhanced phytoremediation of contaminated soils. In: Microbe Mediated Remediation of Environ Contam. ; 2021. p. 177-98.

11. Yadav BK, Siebel MA, van Bruggen JJA. Rhizofiltration of a Heavy Metal (Lead) Containing Wastewater Using the Wetland Plant Carex pendula. Clean Soil Air Water . 2011 May;39(5):46774.

12. Bolan NS, Park JH, Robinson B, Naidu R, Huh KY Phytostabilization. In: Advances in Agronomy . ; 2011. p. 145-204 
13. Susarla S, Medina VF, McCutcheon SC. Phytoremediation: An ecological solution to organic chemical contamination. Ecological Eng . 2002;18(5):647-58.

14. Black H. Absorbing possibilities: phytoremediation. Environal Health Perspectives. 1995;103(12):1106-8.

15. Stomp A-M, Han K-H, Wilbert S, Gordon MP. Genetic improvement of tree species for remediation of hazardous wastes. In Vitro Cellular \& Developmental Biology - Plant. 1993;29(4):227-32.

16. Van Liere H, Staps S, Pijls C, Zwiep G, Lassche R, Langenhoff A. Full scale case: Successful in situ bioremediation of a $\mathrm{HCH}$ contaminated industrial site in central Europe (The Netherlands). 7th Intl HCHS Pesticides Forum. 2003;128-32.

17. Mougin C, Pericaud C, Malosse C, Laugero C, Asther M. Biotransformation of the insecticide lindane by the white rot basidiomycete Phanerochaete chrysosporium. Pestic Sci. 1996;47(1):51-9

18. Hoagland RE, Zablotowicz RM. The role of plant and microbial hydrolytic enzymes in pesticide metabolism. Pesticide Biotransformation in Plants and Microorganisms: Similarities and Divergences. 2001;58-88.

19. Brown HM, Kearney PC. Plant biochemistry, Environal properties, and global impact of the sulfonylurea herbicides. Synth Chem Agrochem II. 1991;32-49.

20. Lamoureux GL, Rusness DG. Pentachloronitrobenzene Metabolism in Peanut. 1. Mass Spectral Characterization of Seven Glutathione-Related Conjugates Produced in Vivo or in Vitro. J Agric Food Chem. 1980;28(6):1057-70.

21. Romano ML, Stephenson GR, Tal A, Hall JC. The Effect of Monooxygenase and Glutathione S-Transferase Inhibitors on the Metabolism of Diclofop-methyl and Fenoxaprop-ethyl in Barley and Wheat. Pest Biochem Physiol. 1993;46(3):181-9.

22. Nichols TD, Wolf DC, Rogers HB, Beyrouty CA, Reynolds CM. Rhizosphere microbial populations in contaminated soils. Water Air Soil Poll. 1997;95(1-4):165-78.

23. Crowley DE, Alvey S, Gilbert ES. Rhizosphere Ecology of Xenobiotic-Degrading Microorganisms. ACS Symposium Series. 1997;664:20-36.

24. Verma H, Kumar R, Oldach P, Sangwan N, Khurana JP, Gilbert JA, et al. Comparative genomic analysis of nine Sphingobium strains: Insights into their evolution and hexachlorocyclohexane $(\mathrm{HCH})$ degradation pathways. BMC Genomics. 2014;15(1)

25. Dubey RK, Tripathi V, Singh N, Abhilash PC. Phytoextraction and dissipation of lindane by Spinacia oleracea L. Ecotoxicol Environ Saf. 2014;109:22-6.

26. Aresta A, Marzano CN, Lopane C, Corriero G, Longo C, Zambonin $\mathrm{C}$, et al. Analytical investigations on the lindane bioremediation capability of the demosponge Hymeniacidon perlevis. Mar Poll Bull. 2015;90(1-2):143-9.

27. Shougang W. Acupuncture for the Treatment of Simple Obesity: Basic and Clinical Aspects . 2012

28. Becerra-Castro C, Kidd PS, Rodríguez-Garrido B, Monterroso C, Santos-Ucha P, Prieto-Fernández Á. Phytoremediation of hexachlorocyclohexane $(\mathrm{HCH})$-contaminated soils using Cytisus striatus and bacterial inoculants in soils with distinct organic matter content. Environ Poll. 2013;178:202-10.

29. Kimbel HJ, Nilsson EE, Skinner MK. Environally Induced Epigenetic Transgenerational Inheritance of Ovarian Disease. In: The Ovary .; 2019 . p. 149-54.

30. Álvarez A, Yañez ML, Benimeli CS, Amoroso MJ. Maize plants (Zea mays) root exudates enhance lindane removal by native Streptomyces strains. Intl Biodeter Biodegrad. 2012;66(1):14-8

31. Lu Y, Yu Y, Zhou R, Sun W, Dai C, Wan P, et al. Cloning and characterisation of a novel 2,4-dichlorophenol hydroxylase from a metagenomic library derived from polychlorinated biphenylcontaminated soil. Biotechnol Lett. 2011;33(6):1159-67.

32. Egerton-Warburton LM, Querejeta JI, Allen MF, Finkelman S1. Mycorrhizal Fungi. In: Encyclopedia of Soils in the Environ; 2005. p. 533-42.

33. Pearce SL, Oakeshott JG, Pandey G. Insights into ongoing evolution of the hexachlorocyclohexane catabolic pathway from comparative genomics of ten sphingomonadaceae strains. G3: Genes, Genomes, Genetics. 2015;5(6):1081-94.
34. Chouychai W, Kruatrachue M, Lee H. Effect of Plant Growth Regulators on Phytoremediation of HexachlorocyclohexaneContaminated Soil. Intl J Phytoremed. 2015;17(11):1053-9.

35. Nanasato Y, Namiki S, Oshima M, Moriuchi R, Konagaya K-I, Seike N, et al. Biodegradation of $\gamma$-hexachlorocyclohexane by transgenic hairy root cultures of Cucurbita moschata that accumulate recombinant bacterial LinA. Plant Cell Rep. 2016;35(9):1963-74.

36. Gong T, Liu R, Zuo Z, Che Y, Yu H, Song C, et al. Metabolic Eng of Pseudomonas putida KT2440 for Complete Mineralization of Methyl Parathion and $\gamma$-Hexachlorocyclohexane. ACS Synth Biol. 2016;5(5):434-42.

37. Asemoloye MD, Ahmad R, Jonathan SG. Synergistic rhizosphere degradation of $\gamma$-hexachlorocyclohexane (lindane) through the combinatorial plant-fungal action. PLoS ONE. 2017;12(8).

38. Tudi M, Daniel Ruan H, Wang L, Lyu J, Sadler R, Connell D, et al Agriculture Development, Pesticide Application and Its Impact on the Environ. IJERPH . 2021;18(3):1112.

39. Deknock A, De Troyer N, Houbraken M, Dominguez-Granda L, Nolivos I, Van Echelpoel W, et al. Distribution of agricultural pesticides in the freshwater Environ of the Guayas river basin (Ecuador). Sci Total Environ.2019;646:996-1008

40. Nageeb M. Adsorption Technique for the Removal of Organic Pollutants from Water and Wastewater. In: Rashed MN, editor Organic Pollutants - Monitoring, Risk and Treatment . InTech; 2013.

41. Manuel A, Shankar K. Hot Electrons in TiO2-Noble Metal NanoHeterojunctions: Fundamental Sci and Applications in Photocatalysis. Nanomaterials . 2021 May 10;11(5):1249.

42. Kouhi A. Integrating Nanotechnology Into Engineered Products In: Reference Module in Biomedical Sci . ; 2018. p. B978012801238365571X.

43. Schrick B, Hydutsky BW, Blough JL, Mallouk TE. Delivery vehicles for zerovalent metal nanoparticles in soil and groundwater. Chem Mater. 2004;16(11):2187-93.

44. Zinovyev SS, Shinkova NA, Perosa A, Tundo P. Dechlorination of lindane in the multiphase catalytic reduction system with $\mathrm{Pd} / \mathrm{C}, \mathrm{Pt} / \mathrm{C}$ and Raney-Ni. Applied Catalysis B: Environal. 2004;47(1):27-36.

45. Singh R, Manickam N, Mudiam MKR, Murthy RC, Misra V. An integrated (nano-bio) technique for degradation of $\gamma-\mathrm{HCH}$ contaminated soil. J Hazmat Mater. 2013;258-259:35-41.

46. Salam JA, Das N. Remediation of lindane from Environ-an overview. Int J Adv Biol Res. 2012;2(1):9-15.

47. Homolková M, Hrabák P, Kolář M, Černík M. Degradability of hexachlorocyclohexanes in water using ferrate (VI). Water Sc Technol. 2015;71(3):405-11.

48. Wu B-Z, Chen G, Yak H, Liao W, Chiu K, Peng S-M. Degradation of lindane and hexachlorobenzene in supercritical carbon dioxide using palladium nanoparticles stabilized in microcellular highdensity polyethylene. Chemosphere. 2016;152:345-52.

49. Yang $\mathrm{C}$, Yu H, Jiang $\mathrm{H}$, Qiao C, Liu R. An engineered microorganism can simultaneously detoxify cadmium, chlorpyrifos, and $\gamma$-hexachlorocyclohexane. J basic Microbiol. 2016;56(7):820-6.

50. Joo SH, Zhao D. Destruction of lindane and atrazine using stabilized iron nanoparticles under aerobic and anaerobic conditions: Effects of catalyst and stabilizer. Chemosphere. 2008;70(3):418-25.

51. El-Khordagui L, Badawey SE, Heikal LA. Application of biosurfactants in the production of personal care products, and household detergents and industrial and institutional cleaners. In: Green Sustainable Process for Chemical and Environal Eng and Sci; 2021. p. 49-96.

52. Pacwa-Płociniczak M, Płaza GA, Piotrowska-Seget Z, Cameotra SS. Environal applications of biosurfactants: Recent advances. Int J Mol Sci. 2011;12(1):633-54

53. Mnif I, Ellouz-Chaabouni S, Ghribi D. Glycolipid Biosurfactants, Main Classes, Functional Properties and Related Potential Applications in Environal Biotechnology. J Polym Environ . 2018 May ;26(5):2192-206.

54. Bezza FA, Tichapondwa SM, Chirwa EMN. Synthesis of biosurfactant stabilized silver nanoparticles, characterization and their potential application for bactericidal purposes. J Hazmat Mater. 2020;393:122319. 
55. Sachdev DP, Cameotra SS. Biosurfactants in agriculture. Appl Microbiol Biotechnol .2013;97(3):1005-16.

56. Scott MJ, Jones MN. The biodegradation of surfactants in the Environ. Biochimica et Biophysica Acta (BBA) Biomembranes.2000;1508(1-2):235-51.

57. Kumar D, Pannu R. Perspectives of lindane $(\gamma-$ hexachlorocyclohexane) biodegradation from the Environ: a review. Bioresour Bioproces. 2018;5(1).

58. Chen J, Ma X, Yao G, Zhang W, Zhao Y. Microemulsion-based anthocyanin systems: effect of surfactants, cosurfactants, and its stability. Intl J Food Proper. 2018;21(1):1152-65.

59. Saez JM, Casillas García V, Benimeli CS. Improvement of lindane removal by Streptomyces sp. M7 by using stable microemulsions. Ecotoxicol Environ Saf. 2017 Oct 1;144:351-9. 